\title{
Reflexões sobre Propostas de Didatização de Gênero ${ }^{1}$
}

Ana Maria de Mattos GUIMARÃES ${ }^{2}$

UNISINOS - Universidade do Vale do Rio dos Sinos

Resumo: Desde a publicação dos Parâmetros Curriculares Nacionais, a noção de gênero como instrumento de ensino-aprendizagem passou a ser um tópico freqüente no debate didático de como ensinar Português. Este trabalho pretende analisar a realidade do ensino fundamental brasileiro nesta questão e mostrar o que significa trabalhar com gêneros textuais, dentro da proposta teórica do interacionismo sociodiscursivo.

Palavras-chave: gênero de texto; modelo didático; seqüências didáticas; interacionismo sociodiscursivo; ensino fundamental.

Abstract: Text/discourse genres have become a frequent topic in the didactic debate on how to teach Portuguese in the Brazilian school context since the publication of National Curricular Parameters. This work seeks to develop an analysis of how the elementary school is dealing with genre and to demonstrate what it means to work with text genres under the perspective of the socio-discursive interactionism. Key words: speech genres; didactic models; didactic sequences; sociodiscursive interactionism; Brazilian school system.

Resumen: Desde la publicación de los parámetros curriculares nacionales, la noción de género como instrumento de ensinoaprendizagen pasó a ser un topico frecuente en el debate didáctico de como enseñar Portugues. Este trabajo pretende analisar la realidad del ensino básico brasileño en esta cuestión y mostrar lo que significa trabajar

\footnotetext{
${ }^{1}$ Este artigo foi apresentado, sob forma de comunicação, no IV Congresso Internacional da ABRALIN, realizado de 17 a 19 de fevereiro de 2005, em Brasília.

${ }^{2}$ Doutora em Lingüística Aplicada, Professora e coordenadora do Programa de Pós Graduação em Lingüística Aplicada da UNISINOS.
} 
con generos textuales, dentro de la propuesta teorica del interaccionismo socio-discursivo.

Palabras claves: género del texto; modelo didáctico; secuencia didáctica; interaccionismo socio- discursivo; sistema escolar brasileño.

\section{Introdução}

Em vigor no Brasil desde 1998, os Parâmetros Curriculares Nacionais, publicados pelo MEC, ao estabelecerem diretrizes curriculares para o Ensino Fundamental brasileiro, apoiaram-se fortemente em concepções teóricas relativamente recentes e inovadoras. A noção de gênero como instrumento de ensino-aprendizagem é central nessa proposição:

Todo o texto se organiza dentro de determinado gênero em função das intenções comunicativas, como parte das condições de produção dos discursos, os quais geram usos sociais que os determinam. (BRASIL, 1998, p. 21)

Gêneros textuais tornaram-se, então, mote freqüente no debate didático do como ensinar Português. Muitas vezes, esta discussão é alimentada por frases do tipo "Mas eu sempre trabalhei com gêneros...", o que, quando o questionamento é levado adiante, permite inferir que se trata de trabalho com os tipos textuais classicamente expostos na escola: narração, descrição, dissertação, ou com textos, dos mais diversos gêneros. Esta apresentação pretende, a partir de um panorama da escola nos dias de hoje, mostrar o que significa o trabalho com gêneros textuais, dentro da proposta teórica do interacionismo sociodiscursivo (BRONCKART, 1999).

\section{$1 \mathrm{Na}$ escola fundamental brasileira trabalha-se, realmente, com gêneros de textos?}

Infelizmente, a resposta a esta questão é negativa. Duas razões levam-me a esta afirmação. A primeira diz respeito a estudo realizado por Luzia Bueno (2002), através da análise de livros didáticos (LD) de $5^{a}$ a $8^{a}$ séries. A segunda fala de pesquisa desenvolvida por 
alunos do Programa de Pós-Graduação em Lingüística Aplicada da UNISINOS, sobre a tarefa em sala de aula. ${ }^{3}$

O trabalho de Luzia analisou todos os LDs recomendados pelo governo, após avaliação do MEC, de 1998 a 2002, portanto, após a vigência dos PCNs. Foram 7 as coleções analisadas, tomando como foco a concepção de gênero como definida na seção 2 deste trabalho. Tendo verificado a preponderância absoluta de textos de gêneros da mídia impressa (notícias, reportagens, notas, classificados, seqüências do narrar) nestes LDs, a autora preocupou-se em cotejar o texto apresentado no LD e o original publicado na mídia. As variantes dos textos originais, sua retextualização pelos autores dos LDs, mostraram alteração no seu estatuto enquanto gênero, em sua significação e em sua inteligibilidade, com mudanças expressivas ocorridas nas camadas textuais, tais como expostas por Bronckart, 1999. Assim, mesmo os livros que se propõem dar conta da proposta didática básica dos PCNs mostram desconhecer o fundamento de que os gêneros constituem um ponto de comparação que situa as práticas de linguagem, pois, uma vez utilizada a prática de retextualização, como mostrada no trabalho de Luzia, perdem-se as características do gênero original e tem-se presente outro gênero, que poderíamos até chamar de "texto de LD".

O trabalho dos alunos do PPG foi uma pesquisa de campo para análise de como professores de língua materna concebiam tarefas, no sentido preconizado por Dolz et al (2002) de que "colocar tarefas no centro dos debates dos didáticos significa tentar saber o que se faz nas práticas de sala de aula." Foram 9 classes pesquisadas, em 6 diferentes escolas do Rio Grande do Sul. Também variaram os níveis dessas classes: de turmas do EJA a classes regulares de $2^{\mathrm{a}}$ a $6^{\mathrm{a}}$ séries, de escolas públicas a escolas privadas. Os trabalhos são testemunhas de uma concepção de ensino tradicional, com uma variação do grau de interação professor-aluno, mas em que a presença do texto é meramente uma ilustração de um ponto gramatical, sem que haja

\footnotetext{
${ }^{3}$ Agradeço a colaboração das mestrandas Andréa Scaffaro, Carmen Quadros, Carmen Lazarotto, Cleusa Santos, Daiana Campani, Juliana Camargo de Souza, Maria Paula Brock, Sandra Pacheco da Costa, Stefanie M. Moreira e Vanessa Damasceno, no levantamento dos dados sobre tarefas.
} 
absolutamente um trabalho consistente, que aborde a questão gênero. Os dois cenários, montados através de depoimentos de professores que foram entrevistados para este trabalho, demonstram o caráter tradicional das práticas docentes de Língua Portuguesa:

Cenário 1: ${ }^{4}$

Professora de Lingua Portuguesa de $6^{a}$ série de escola particular de cidade do interior do Rio Grande do Sul, formada em Letras há 6 anos:

P: No $1^{\circ}$ bimestre... nós... trabalhamos... com narrativa. Lembram... (Ruídos vários, os alunos estão se acomodando). Lembram o que é uma narrativa?

As: $\operatorname{Sim} ! !$

P: O texto para ser considerado uma narrativa precisa ter...? Vou encontrar narradores?... Quando o narrador é personagem? ... Que tipos de narradores existem?...

Este cenário mostra a preocupação com o tipo textual (no caso a narração), visto pelo seu aspecto estrutural, ou seja, pela identificação de algumas de suas características. Enfatiza um conteúdo, aparentemente já trabalhado anteriormente, numa dimensão prescritiva. É uma tarefa que envolve avaliação dos conhecimentos dos alunos que a pergunta da professora se propõe revelar.

Cenário 2: ${ }^{5}$

Professora-estagiária de Lingua Portuguesa em Escola Municipal de cidade da Grande Porto Alegre, aluna de $5^{\circ}$ semestre de Faculdade de Letras da mesma cidade:

P: Normalmente eu pego textos (. ) de livros ou jornal agora até tô começando a trabalhar mais com textos jornalísticos até agora tava trabalhando poema, e aí as questões eu mesma elaboro. Dificilmente eu pego questões pro::ntas de (. ) livro didático porque eu não::: não gosto muito.

${ }^{4} \mathrm{~A}$ transcrição refere-se à introdução da tarefa que será proposta pela professora ao grupo de alunos.

${ }^{5} \mathrm{~A}$ transcrição refere-se à fala da professora-estagiária em resposta à pergunta de como organizava as tarefas em sua sala de aula. 
P: Eu eu vou dizer o que eu uso né (. ) o que eu tenho como maior objetivo assim que eu acho que é eles saberem usar as classes gramaticais dentro de um texto $($.$) eles saberem identificar dentro de um texto$ que é onde eles não conseguem é a gramática textual (. ) é conseguir trabalhar a gramática textual com os alunos.

Dentro do cenário 2, uma das tarefas solicitadas pelo professor envolveria as capacidades de linguagem ${ }^{6}$ dos alunos em relação ao gênero de texto carta. Tratava-se de uma questão sobre escreverem uma carta para alguém que não viam há muito tempo, na qual os alunos não obtiveram sucesso, ainda que fosse realizada em grupo. Muitos grupos chegaram, inclusive, a escrever uma frase apenas, como se fosse um simples bilhete. A situação evidencia que, ao invés de enfatizar exercícios de classificações gramaticais, seria necessário que a professora auxiliasse no desenvolvimento das habilidades de linguagem dos alunos relacionadas ao gênero em questão, a carta social, a fim de que, conforme Schnewly e Dolz (2004, p. 80), eles pudessem

melhor conhecê-lo [o gênero], ou apreciá-lo, [...] melhor compreendê-lo, [...] melhor produzi-lo na escola ou fora dela e [...] desenvolver capacidades que ultrapassem o gênero e que são transferíveis para outros gêneros próximos ou distantes.

E nenhum trabalho sobre carta foi realizado na aula, a não ser a seguinte explicação da docente, após dúvidas dos alunos:

P: Só um pouquinho, deixa eu explicar a número 9 de novo. Todos escutem. Na número 9 que vocês tem que escrever uma ca::rta, vocês vão ter que colocar pra que:m é essa carta, não podem esquecer. Colocar o nome da pesso::a ( . ) ta? pra quem vocês vão escrever.

\footnotetext{
${ }^{6}$ Capacidade de linguagem foi utilizada de acordo com conceito de Dolz e Schneuwly (2004, p. 53), segundo o qual a noção evoca as aptidões necessárias do aluno para a produção de um gênero numa situação de interação: "adaptarse às características do contexto e do referente" "mobilizar modelos discursivos" e "dominar as operações psicolingüísticas e as unidades lingüísticas".
} 
A realidade encontrada nessa sala de aula vai ao encontro das considerações de Bezerra (2002, p. 41): a escola sempre trabalhou com gêneros, "mas restringe seus ensinamentos aos aspectos estruturais ou formais do texto". Ou seja, um gênero foi introduzido (a professora não pode ser acusada de não trabalhar com textos!), mas a tarefa elaborada com base nesse gênero evidenciou que ele não foi o objeto de ensino. Ele foi um meio de avaliar se os alunos tinham aprendido o real objeto de ensino com que eles estavam trabalhando há algumas aulas, ou seja, as classes gramaticais. Representa, prototipicamente, o fato de que a proposta pedagógica relativa a gêneros textuais não ter sido apropriada pelos docentes da escola brasileira.

\section{De que Gênero de Texto Estamos Falando?}

O ponto de partida para a discussão dessa noção é estabelecido por Bakhtin, quando introduz a questão sobre gêneros do discurso:

A utilização da língua efetua-se em forma de enunciados (orais e escritos),... . O enunciado reflete as condições específicas e as finalidades de cada uma dessas esferas, não só por seu conteúdo (temático) e por seu estilo verbal, ou seja, pela seleção operada nos recursos da língua - recursos lexicais, fraseológicos e gramaticais -, mas também, e sobretudo, por sua construção composicional. Estes três elementos (conteúdo temático, estilo e construção composicional) fundem-se indissoluvelmente no todo da enunciação, e todos eles são marcados pela especificidade de uma esfera de comunicação. Qualquer enunciado considerado isoladamente é, claro, individual, mas cada esfera de utilização da língua elabora seus tipos relativamente estáveis de enunciados, sendo isso que denominamos gêneros de discurso (BAKHTIN, 1979, p. 279).

Esta noção foi o ponto de partida para os trabalhos do interacionismo sociodiscursivo (ISD), que recolocam a questão do gênero, sob o rótulo de gêneros textuais (BRONCKART, 1999), perseguindo a idéia de que tais gêneros podem ser facilmente reconhecidos nas práticas sociais de linguagem. Caracterizados por sempre apresentarem tema, construção composicional e estilo específicos, os gêneros tornam a comunicação humana possível. 
Embora a teoria oscile, por vezes em seu tratamento (como bem mostra artigo de Machado, 2004), sua relação com a escola é reafirmada em artigo de Schneuwly e Dolz (2004, p. 74), quando consideram que "é através dos gêneros que as práticas de linguagem materializam-se nas atividades dos aprendizes". Essa releitura do conceito de gênero, sistematizada, sob o ponto de vista da realidade escolar, por Schneuwly e Dolz (1999), enfatiza a questão de sua utilização enquanto um instrumento de comunicação em uma determinada situação, mas, ao mesmo tempo, um objeto de ensino/aprendizagem. Tais autores desenvolvem a hipótese de que "quanto mais precisa a definição das dimensões ensináveis de um gênero, mais ela facilitará a apropriação deste como instrumento e possibilitará o desenvolvimento de capacidades de linguagem diversas que a ele estão associadas" (idem, p. 15). Ainda segundo eles (2004, p. 75), o gênero "pode ser considerado como um megainstrumento que fornece um suporte para a atividade nas situações de comunicação, e uma referência para os aprendizes".

\section{O Que Significa Trabalhar com Gênero de Texto na Escola?}

Em primeiro lugar, é preciso considerar que a introdução de um gênero de texto na escola depende de uma decisão didática, que precisa considerar os objetivos de sua aprendizagem, tratando-se, simultaneamente de "um gênero a aprender, embora permaneça gênero para comunicar" (SCHNEUWLY; DOLZ, 2004, p. 81). Essa relação estará na base de um modelo didático de gêneros, que definirá os princípios (por exemplo, o plano geral do gênero de texto escolhido), os mecanismos enunciativos que se põem em ação e as formulações lingüísticas, ou seja, os mecanismos de textualização que devem constituir os objetos de aprendizagem dos alunos. Três são os aspectos a serem considerados nesta elaboração: os conhecimentos existentes sobre gêneros de texto (teoricamente variados e heterogêneos); as capacidades observadas dos aprendizes (daí a relevância de a própria docente da classe ser participante da pesquisa) e os objetivos de ensino. Finalizado o modelo didático, estará definido, então, o saber a ser ensinado. Este modelo didático, definido por Schneuwly e Dolz (2004), assenta-se, pois, sobre um tripé, formado por: 
- conhecimentos de referência;

- objetivos de ensino;

- capacidades observadas dos aprendizes.

A construção deste modelo é a primeira etapa a ser desenvolvida para o trabalho com gêneros na sala de aula. Após será elaborada seqüência didática referente às diferentes atividades previstas para sala de aula.

A seqüência didática (DOLZ; NOVERRAZ; SCHNEWLY, 2004, p. 95-128) deve partir de uma produção inicial, em que os alunos tentam elaborar um primeiro texto do gênero escolhido, de forma a revelar as representações que têm dessa atividade. Essa produção é realizada após discussão de um projeto coletivo de produção de um gênero escrito, posto como um problema de comunicação a ser resolvido, seguida de uma apresentação dos conteúdos deste gênero. Ela é a pista para a preparação de diversos módulos, que darão conta dos problemas que apareceram na primeira produção, de forma a dar aos alunos os instrumentos necessários para atingirem o objetivo de produzirem o gênero de texto escolhido. A seqüência será finalizada por uma produção final, que dá ao aluno a oportunidade de praticar as noções e instrumentos trabalhados durante os módulos e permite ao professor uma avaliação do processo.

\section{Uma Experiência Bem Sucedida}

O projeto que atualmente desenvolvo, intitulado "Desenvolvimento de narrativas e a construção social da escrita" objetiva aproximar as pesquisas pensadas sob o prisma de aquisição e desenvolvimento da linguagem para o contexto escolar, transpondoas para uma reflexão pedagógica, a partir do acompanhamento longitudinal de dois grupos de alunos, da $3^{\text {a }}$ até a $5^{\text {a }}$ séries. Num desses grupos é desenvolvido todo um trabalho de intervenções formativas; o outro é o grupo controle. A escola onde se desenvolve é municipal, na periferia de uma cidade da região metropolitana de Porto Alegre, e a maioria dos alunos que a freqüenta é de classes menos favorecidas, no máximo, de classe média baixa. Trata-se de uma escola pequena, em que funciona apenas 1 turma por série, do pré até a $5^{a}$ série. A experiência a seguir relatada fez parte deste projeto e se desenvolveu na turma experimental, então na $3^{a}$ série. 
Foi escolhida a narração como tipo de discurso constitutivo das atividades de linguagem a que nos dedicaríamos. Um dos aspectos envolvidos diz respeito a como se estruturam as narrativas, o que significa ter em mente um esquema narrativo, como apresentado por Adam, 1985 e Labov, 2001. Esse último conceitua narrativa mínima como aquela que tem uma complicação e uma resolução.

A análise dos textos anteriormente produzidos pela turma apontou que, mesmo sob o rótulo de narrativa e a partir de título sugestivo: "Um passeio inesquecível", faltava a todos a característica mais marcante da ação complicadora. Também grande parte das narrativas orais produzidas durante as entrevistas faz um relato de ações, sem uma ação complicadora:

*SUY:10 anos Ah, é a do Puff que eu me lembro, a do Patinho Feio não é tão boa assim. Ah @ i , o Puff no livrinho dizia que ele era um ursinho que era muito feliz, que ele pulava de um lado pro outro com seus amigos que era o Tigrão, o Porco, se eu não me engano é o Coelho e eu não sei os outros que tem.Ah@i que ele era muito feliz, que ele pulava, no anoitecer ele ia pra casa, ele tomava banho, fazia seus dever(es) de casa, e no outro dia, ele alevantava de manhã, tomava banho, se arrumava e ia pro colégio e aí depois que ele chegava do colégio ele ia brincar de novo e aí depois de noite ele www \# só me lembro essa parte

Planejei, em conjunto com a professora, uma proposta de trabalho com gêneros textuais em seqüências didáticas, com base em Schneuwly e Dolz (2004), Schneuwly (2002), Bronckart (1999), Cordeiro, Azevedo e Mattos (2004), Machado (2000). Foram, então, consideradas as regularidades do uso desse gênero em diferentes atividades de linguagem, sob um triplo ponto de vista: a) dos conteúdos e conhecimentos veiculados pelo texto; b) das estruturas comunicativas comuns aos textos vistos como pertencentes ao gênero escolhido; c) das configurações específicas das unidades lingüísticas que compõem o texto (SCHNEUWLY; DOLZ, 2004), para permitir a construção do modelo didático que seria utilizado.

O gênero escolhido foi o de contos de fadas, pelo interesse que as crianças, na entrevista, revelaram ter na leitura de títulos desse 
gênero. Inicialmente, caracterizou-se o gênero de referência, para estudar como transformá-lo em objeto de aprendizagem. Fica sempre marcante a necessidade de ultrapassar o que Schneuwly (2002, p. 238-239) caracteriza como gênero escolar, marcado pelo fato de pertencer, simultaneamente, a dois lugares sociais: o da situação de referência que tenta reproduzir o tema proposto e o da situação escolar da escrita, "definida notadamente pelo fato de que o aluno deve escrever para mostrar que ele sabe escrever e por aprender a escrever, de que escreve a mesma coisa e, ao mesmo tempo, que numerosos outros de seus codiscípulos, de que ele sabe que seu texto corresponde a uma ficção de situação à qual ele pode se identificar mais ou menos.", sem que se efetive uma troca comunicacional. Para tal fim, procurou-se, inicialmente, refletir sobre a "escolarização" do gênero de referência.

O gênero "conto de fadas" é considerado um gênero simples (CANVAT, 2003, p. 173-174), no qual pode operar uma relação de conformidade, isto é, de duplicação, entre o texto e seu gênero, por se tratar de um gênero fortemente restringido por fórmulas prédeterminadas pela tradição. $\mathrm{O}$ uso de recursos lingüísticos é simples e direto. Os nomes de seus personagens representam as suas características (Bruxa Onilda). As palavras formam uma imagem visual, principalmente na descrição de elementos fantásticos e mágicos. A metamorfose das personagens, a magia, o encanto, o uso de talismãs e a força do destino são também constantes neste gênero (JOLLES, 1993). Os contos de fada clássicos apresentam o mesmo esquema narrativo, no qual as dificuldades materiais do personagem são apresentadas na situação inicial. A partir do desenvolvimento da ação, esse cotidiano é alterado pela interferência do elemento mágico, o que permite a emancipação do herói e o clássico final feliz na resolução e na situação final. As personagens são planas, geralmente poucas e sem complexidade psicológica. São, na maioria, jovens em idade de casar. As qualidades físicas ou morais são nítidas em cada personagem. O tempo e o espaço são indeterminados, por isso, são comuns expressões genéricas do tipo: "era uma vez", "há muito tempo", "num certo dia" e "num lugar distante" (ZILBERMAN, 1982) Observe-se que se optou pelo uso de contos de fadas ditos renovados, em lugar dos tradicionais, para permitir uma melhor inserção do mágico na realidade atual. 
A seqüência didática sobre o gênero conto de fadas foi organizada em 7 oficinas, a partir de uma ordem determinada para dar conta da dificuldade que se pretendeu vencer (a ausência de complicação no texto narrativo). Foi explicado aos alunos que eles teriam "oficinas de ESCREVER" por 2 meses. Nelas estudariam os contos de fada, sendo desenvolvidas atividades para que refletissem sobre suas características e pudessem produzir eles mesmos contos de fadas, com acontecimentos mágicos.

O primeiro texto produzido por eles não teve orientação específica, a não ser que deveriam apresentar um personagem inventado que se encontraria com uma bruxa. $\mathrm{Na}$ análise desse primeiro texto, foi possível verificar que a maioria mostrou conhecimento sobre a magia como componente básico dos contos de fada, mas, em grande parte não foi possível caracterizar a mudança de uma situação inicial, que se dá, sobretudo, por uma ação complicadora. Nas produções finais, foi possível checar a reversão desta análise inicial.

Os módulos que compuseram as oficinas ficaram constituídos como segue:

Oficina 1: O que é um conto de fadas?

Apresentação da personagem que acompanhará o trabalho, a partir da distribuição do livro As memórias da Bruxa Onilda (LARREULA; CAPDEVILLA, 2002). Leitura comentada da história. Exploração das principais características do gênero: a presença da magia e do encanto; os personagens típicos, as características de tempo e espaço indeterminados; os nomes típicos dos personagens; os momentos de apresentação dos personagens e suas dificuldades na situação inicial; a presença de uma complicação que atua sobre a situação inicial, a interferência do elemento mágico para resolução deste problema; o final feliz.

Escolha pelas crianças de um personagem para os seus contos de fada, que os acompanhará em todas as oficinas. Escrita de texto com a descrição deste personagem e apresentação à classe. Distribuição da história: No zoológico, com novas aventuras da Bruxa Onilda, para leitura em casa e escrita de um conto semelhante com seu personagem. 
Oficina 2: Nós podemos escrever um conto de fadas

A partir do sorteio de um dos personagens inventados, composição coletiva de uma narrativa em que a Mulher Gata se encontra com a Bruxa Onilda, mediante proposta oral de segmentos, seguida de escrita no quadro. O objetivo da oficina foi entender o que é um conto de fadas (presença do mágico) e sua característica de complexidade (vários acontecimentos) e a obrigatoriedade de conflito (marca do enredo).

Oficina 3: Um conto de fadas apresenta vários acontecimentos (modificação da situação inicial e ações que respondem à nova situação)

Análise da história A guerra, sob o ponto de vista de seu enredo. Escrita no quadro dos "grandes acontecimentos". Em grupos de 4, elaboração de uma história coletiva com grandes acontecimentos, que envolvam o personagem da capa de seus cadernos (personagens galácticos, que determinaram a separação dos grupos) e a Bruxa Onilda. Leitura e avaliação dessas histórias realizadas pelo conjunto da turma, a partir do critério de apresentarem vários acontecimentos, terem um enredo, um conflito.

Oficina 4: É preciso reescrever o texto para que ele se aperfeiçoe.

Introdução do procedimento de reescrita dos textos. Foi escolhido, aleatoriamente, um dos textos de cada grupo já analisado tematicamente na aula anterior, que foi copiado tal e qual em folha especial. Cada aluno leu individualmente o texto recebido e assinalou o que imaginava ser um erro, escrevendo a forma certa ao lado. Após, em conjunto, foram assinalados os problemas, devendo reescrevê-los corretamente no quadro quem o descobrisse. ${ }^{7}$

\footnotetext{
${ }^{7}$ Vencidos os problemas ortográficos (letra maiúscula e trocas), passou-se a outros questionamentos. Nenhuma criança apontou problemas de pontuação (blocos de oração estavam presentes em todos os textos), mas foram capazes de identificar os casos de discurso direto e corrigiram essas marcas. Mesmo a necessidade de ponto de interrogação não foi percebida e teve que ser assinalada por mim, a partir de dramatização de leitura. Os problemas referentes aos blocos de oração, por entender que mereciam um estudo à parte, uma vez que nenhum leitor se ocupou disso, fizeram parte de seqüência didática desenvolvida posteriormente, a respeito do gênero 'peça de teatro infantil'.
} 
Oficina 5: Colocando palavras, melhora...

A partir de 2 histórias mudas em seqüência (Furnari, 2002), leitura oral dos quadrinhos e escrita posterior, sempre reafirmando os elementos necessários para um conto de fadas. Avaliadas algumas das histórias escritas sob o ponto de vista de terem (ou não) reproduzido os acontecimentos dos quadrinhos e de apresentarem os elementos necessários para gênero. A história mais complexa foi dramatizada, como forma de avaliar sua compreensão.

Oficina 7: Producão final

Produção de um conto de fadas, que trouxesse novas aventuras da Bruxa Onilda e apresentasse todas as características estudadas. Esse texto foi lido também por duas outras professoras: a supervisora educacional e a professora da classe. Deles foram escolhidos 3 contos que foram publicados como um livro infantil e distribuídos a todos.

A avaliação das produções finais dos alunos demonstrou que o objetivo de construção de um texto inserido no gênero de escolha foi atingido. Apresenta-se, a seguir, uma análise preliminar dessas produções, a partir da proposta de Bronckart (1999). Essa análise preliminar tratou do que chama de "infra-estrutura geral", ou seja, o nível mais profundo do texto, de acordo com o gênero de texto escolhido, a pertinência do conteúdo temático desenvolvido no texto e as seqüências que o organizam. Foram investigadas as seguintes características (apresentadas junto ao percentual de ocorrências): 


\section{Léxico típico:}

Marcas temporais indefinidas (era uma vez, um dia....) $=70,6 \%$ Nome de personagem representativo de suas características $($ Bruxa Onilda, fada xx, $)=100 \%$

Nomes que remetam diretamente ao conto de fadas (castelo, vassoura de bruxa) $=88,2 \%$

\section{Situações típicas:}

Presença de encantamento, magia $=100 \%$

Interferência do elemento mágico no cotidiano $=70,6 \%$

Personagens típicos: (excluindo-se a Bruxa, presente na proposta do texto)

Outros personagens mágicos (Vampiro, Frankenstein, Homem

Aranha,...) $=41,2 \%$

Antagonistas $=47,1 \%$

Protagonistas $=100 \%$

Seqüência narrativa (ADAM, 1985)

\section{Situação inicial}

- Momento: 88,2\% (um dia, era uma vez, no dia das bruxas...)

- Lugar: 65\% (castelo, praia, rua, floresta, casa da bruxa...)

- Personagens : 100\% (de 2 a 6 personagens)

- Dificuldades do personagem $=65 \%$ 


\section{Complicação}

- Evento modificador da situação inicial $=100 \%$

- Metamorfose dos personagens : $53 \%$

Ações variadas

- Diversidade de ações $=70,6 \%$

- Interferência do elemento mágico no cotidiano : 65\%

\section{Resolução}

Resolução da complicação $=94,1 \%$

\section{Situação final}

- Final feliz: $88,2 \%$

- Novo estado de equilíbrio $=88,2 \%$ (majoritariamente ligada à resolução, tipo "viveram felizes para sempre")

Comparando-se os resultados da produção inicial com a final, pode-se projetar um gráfico, como o a seguir apresentado, que mostra a grande diferença entre a representação do escrever como "escrever texto", verbalizada pelas crianças na entrevista individual e manifestada na sua primeira produção, e a apropriação do gênero conto de fadas, que ocorre após a realização das oficinas. 


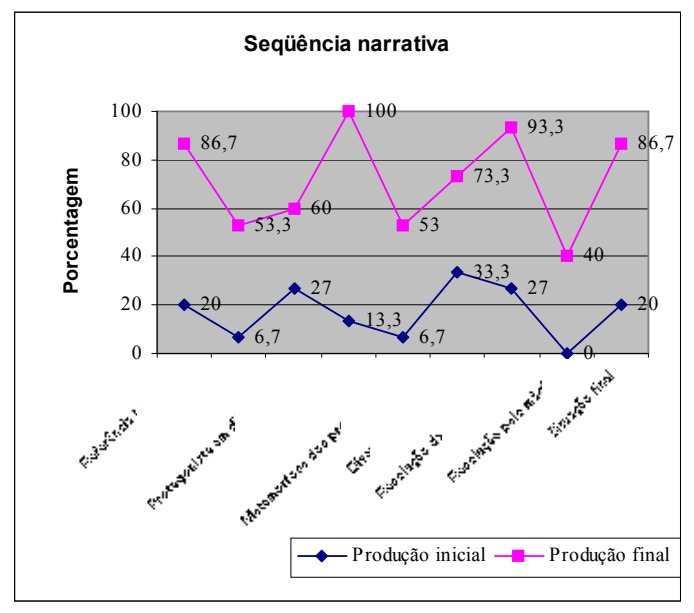

Esses resultados dão-nos alento para a continuidade do projeto, ainda mais que, na primeira produção analisada não havia mostras de que os alunos conheciam os elementos da seqüência narrativa, muito certamente, em função de que não era tratada adequadamente a questão de produção de qualquer tipo de texto. Nesse sentido, a presença da seqüência narrativa se mostra muito evidente, pelos percentuais elevados em todos os seus elementos. A escolha de um gênero considerado simples, como é o caso dos contos de fada, certamente contribuiu para este desempenho.

Por outro lado, há problemas de língua, como ortografia e pontuação, que se mantiveram e precisarão ser corrigidos com a evolução do trabalho. Para isso, estão sendo planejadas novas seqüências didáticas de forma a refletir sobre uma aprendizagem da escrita que permita ir além do fato de que "escrever se aprende escrevendo". O trabalho até agora desenvolvido comprovou a afirmação de Schneuwly (2002) de que se aprende a escrever a partir da apropriação dos utensílios da escrita, no sentido vygotskiano de que essa apropriação permite transformar a relação com o próprio processo psíquico da produção de linguagem: "As pesquisas em didática mostram que o cacife da aprendizagem da escrita - e, conseqüentemente, de sua aprendizagem - é a transformação do sistema pela construção de um novo sistema que reorganize de outra forma os diferentes componentes que intervêm na produção de um texto" (op.cit, p. 242). 
$\mathrm{Na}$ seqüência didática, o papel do professor é fundamental. Essa foi justamente a maior dificuldade encontrada na experiência relatada, em que tive de assumir tal papel, pois o professor de classe entendia ser impossível esta tarefa. Ainda que tenha conseguido manter uma ótima interação com ele, seu desânimo de docente em final de carreira, com remuneração escassa e formação de ensino médio, levou-o a decidir participar como observador da experiência. Os resultados animaram-no, mas não garantiram sua adesão. De qualquer modo, continuo acreditando que o caminho para mudar a realidade da escola brasileira é um trabalho de formação sério, que envolva prática docente e avaliação dessa prática, um fazer e refazer das ações de linguagem, numa interação entre pesquisadores de ensino de língua materna, preocupados em também serem formadores de docentes e os próprios professores da Escola Fundamental.

\section{Referências Bibliográficas}

ADAM, J. M. Le texte narratif. Paris: Nathan, 1985.

BAKHTIN, M. Estética da criação verbal. São Paulo: Martins Fontes, 1979.

BEZERRA, M. A. Ensino de língua portuguesa e contextos teóricometodológicos. In: DIONÍSIO, A.; MACHADO, A. R.; BEZERRA, M. A. Gêneros textuais e ensino. Rio de Janeiro: Lucerna, 2002. p. 37-46.

BRASIL. Ministério da Educação. Secretaria de Educação Fundamental. Parâmetros curriculares nacionais de língua portuguesa: terceiro e quarto ciclos do ensino fundamental. Brasília: MEC, 1998.

BRONCKART, J. P. Atividade de linguagem, textos e discursos: por um interacionismo sócio-discursivo. São Paulo: EDUC, 1999.

BUENO, L. Gêneros da mídia impressa em livros didáticos para os $3^{\text {os }}$ e $4^{\text {os }}$ ciclos do Ensino Fundamental. 2002. Dissertação (Mestrado em Lingüística Aplicada) - Universidade Estadual de Campinas - UNICAMP, Campinas. 
CANVAT, K. L'écriture et son apprentisage : une question de genres? Etat des lieux et perspectives. Pratiques, n. 117/118, p. 171-180, jun. 2003.

CORDEIRO,G. S.; AZEVEDO, I. C.; MATTOS, V. Trabalhando com seqüências didáticas: uma proposta de ensino e de análise de narrativas de viagens. Calidoscópio, São Leopoldo, v. 2, n. 1, p. 15-27, jun. 2004.

DIONISIO, A. Gêneros textuais e ensino. Rio de Janeiro: Lucerna, 2002.

DOLZ, J. et al. Les tâches et leurs entours. Anais DFLM2001, 2002. 1 CD-ROM.

FURNARI, E. A Bruxinha e o Gregório. São Paulo: Ática, 2002.

GUIMARÃES, A. M. M. Desenvolvimento de narrativas e o processo de construção social da escrita. Calidoscópio, São Leopoldo, v. 2, n. 2, p. 67-74, dez. 2004.

JOLLES, A. Formas simples. São Paulo: Cultrix, 1993.

LABOV. W. Uncovering the event structure of narrative. Georgetown University Round Table 2001. Georgetown: Georgetown Un. Press, 2001.

LARREUlA, E.; CAPDEVIllA, R. As memórias da Bruxa Onilda. 10. ed. São Paulo: Scipione, 2002.

MACHADO, A. R. Para (re-)pensar o ensino de gêneros. Calidoscópio, São Leopoldo, v. 2, n. 1, p. 17-28, jun. 2004.

SCHNEUWLY, B . L'écriture et son apprentissage: le point de vue de la didactique. Éléments de synthèse. Pratiques, Metz, n. 115/116, p. 237-53, dez. 2002.

. ; DOLZ, J. Gêneros orais e escritos na escola. Campinas: Mercado de Letras, 2004.

ZILBERMAN, R. Literatura infantil: autoritarismo e emancipação. São Paulo: Ática, 1982. 